\title{
Elevated High Sensitivity C-Reactive Protein Is Associated with Type 2 Diabetes Mellitus: The Persian Gulf Healthy Heart Study
}

\author{
IRAJ NABIPOUR, KATAYOUN VAHDAT, SEYED MOJTABA JAFARI, SAEIDEH BEIGI, MAJID ASSADI, \\ FATEMEH AZIZI AND ZAHRA SANJDIDEH
}

Department of Endocrine and Metabolic Diseases, The Persian Gulf Tropical Medicine Research Center, Bushehr University of Medical Sciences, Bushehr P. O. Box-3631, I. R. Iran

\begin{abstract}
Previous studies have suggested that low-grade systemic inflammation is involved in the pathogenesis of type 2 diabetes mellitus. However, limited information is available about the relationship of diabetes mellitus and inflammation in Asia. We examined the association between high-sensitivity C-reactive protein (CRP) levels and diabetes in a general Iranian population. In an ancillary study to the Persian Gulf Healthy Heart Study, a cohort study of men and women aged $\geq 25$ years, a random sample of 1754 (49.2 percent males, 50.8 percent females) subjects were evaluated. High sensitivity $\mathrm{C}$-reactive protein was measured by enzyme-linked immunosorbent assay. Elevated serum CRP was defined as more than $3.0 \mathrm{mg} / \mathrm{l}$. The diabetes classification was based on the criteria of the American Diabetes Association. A total of 8.6 percent of the subjects ( 8.0 percent of males \& 9.1 percent of females; $p>0.05$ ) had type 2 diabetes mellitus. Geometric mean of CRP was $1.94 \mathrm{mg} / \mathrm{l}(3.80 \mathrm{SD})$ in the studied population. The subjects with diabetes had a higher geometric mean of CRP levels than the subjects with no diabetes [3.67 (SD 3.71) versus 1.85 (3.83) respectively; $p<0.0001$ )]. In multiple logistic regression analysis, diabetes showed a significant age-adjusted association with elevated CRP levels [Odds Ratio $=2.03$, Confidence Interval $(1.38-2.98) ; \mathrm{p}<0.0001]$ after adjusting for sex, LDL-cholesterol, HDL-cholesterol blood pressure, smoking and body mass index. In conclusion, beyond traditional cardiovascular risk factors, elevated CRP is significantly correlated with diabetes in general population of the northern Persian Gulf. Further insight into the specific effects of proinflammatory cytokines and acute-phase proteins will be essential for the development of new preventive strategies for diabetes mellitus.
\end{abstract}

Key words: Diabetes, C-reactive protein, Inflammation, Cardiovascular, Obesity

(Endocrine Journal 55: 717-722, 2008)

DESPITE more than 100 million patients affected worldwide and a dramatic socioeconomic burden due to vascular complications, the etiology of type 2 diabetes is not yet completely understood. It has been hypothesized that type 2 diabetes is a manifestation of an ongoing acute-phase response that is primarily characterized by alterations of the so-called acute-phase proteins, such as C-reactive protein (CRP) [1, 2].

Cross-sectional studies have shown that elevated CRP levels correlate significantly with features of the

Received: January 22, 2008

Accepted: March 20, 2008

Correspondence to: Iraj NABIPOUR, M.D., The Persian Gulf Tropical Medicine Research Center, Boostan 19 Alley, Imam Khomeini Street, Bushehr, I.R. Iran metabolic syndrome, including indexes of adiposity, hyperinsulinemia and insulin sensitivity index, hypertriglyceridemia, and low HDL cholesterol [3-5]. Recently, it was shown that high sensitivity CRP inversely correlated with adiponectin in apparently healthy Japanese men [6]. Prospective studies have also shown that CRP is associated with the risk of diabetes [7].

Numerous studies from various parts of the world have clearly established that CRP predicts future risk for cardiovascular diseases in apparently healthy persons, independent of established risk factors in the majority of studies [8]. In the studies to date, CRP has been shown to predict myocardial infarction, coronary artery disease (CAD) death, stroke, peripheral arterial disease, sudden death, etc [9]. Thus, the Centers for 
Disease Control and the American Heart Association have issued a statement recommending that patients at intermediate risk of CAD might benefit from measurement of CRP [10].

Patients with type 2 diabetes have a markedly increased atherosclerotic risk. Although this increased risk has previously been attributed mainly to hyperglycemia, dyslipidemia, and a prothrombotic state, recent observations in apparently healthy individuals have focused attention on inflammatory mechanisms that may be relevant in patients with diabetes as well [11]. High plasma levels of CRP were associated with an increased risk of incident cardiovascular events among diabetic men, independent of currently established lifestyle risk factors, blood lipids, and glycemic control [12].

Recently, we showed that beyond traditional cardiovascular risk factors, concomitant chronic infection and elevated CRP are significantly correlated with coronary artery disease in the general population [13]. However, data on CRP and diabetes are limited in Asia $[14,15]$. Thus, we examined the relationship of preexisting type 2 diabetes with elevated CRP in a population-representative sample of Iranian adults in the northern Persian Gulf region.

\section{Methods}

\section{Community sampling and baseline examinations}

The Persian Gulf Healthy Heart Study was designed to determine the risk factors for cardiovascular diseases among the northern Persian Gulf population (Bushehr and Hormozgan Provinces) and to develop communitybased interventional projects to change the lifestyles of the population and to present the rising threat of CVD in the region. In phase I of the study, a multiple-stage stratified cluster random sampling technique was used to select 3000 people aged $\geq 25$ years from major ports of Bushehr Province (an Iranian province with the greatest boarder with the Persian Gulf). The studied ports of the northern Persian Gulf were Bushehr Port, Genaveh and Deilam Ports. Specifications dictated that approximately two persons per selected household could be included in phase I cross-sectional survey. Publicity concerning the study appeared in the local newspapers and on the TV. The selected $\geq 25$ years of households were informed about the study through a letter given door-to-door by the survey groups. After a primary education about CVD and its associated risk factors, they were invited to participate in the screening program in a $12-14-\mathrm{h}$ fasting state in the following morning to one of local health services center belonging to Bushehr University of Medical Science.

In an ancillary study to the Persian Gulf Healthy Heart Study, we investigated the correlation between diabetes and elevated $\mathrm{C}$-reactive protein (CRP) in 1754 participants. Examinations were conducted in 2003-2004. Blood pressure was assessed twice at the right arm after a 15-min rest in the sitting position, using a standard mercury sphygmomanometer. Height and weight were measured using a stadiometer. Heavy outer garments and shoes were removed before measuring height and weight. Body Mass Index (BMI) was calculated.

Hypertension was defined according to the WHO criteria (systolic blood pressure $>=140 \mathrm{mmHg}$, diastolic blood pressure $>=90 \mathrm{mmHg}$, or use of antihypertensive medication).

Smoking was considered to be present when the subject smoked cigarette or using of hubble-bubble in a regular daily fashion. Obesity was defined with BMI $>=30$; for anthropometric evaluations [16].

\section{Biochemical measurements}

A fasting blood sample was taken, all samples were promptly centrifuged, separated and analyses were carried out at the Persian Gulf Health Research Center on the day of blood collection using a Selectra 2 autoanalyzer (Vital Scientific, Spankeren, The Netherlands). Glucose was assayed by enzymatic (glucose oxidase) colorimetric method using a commercial kit (Pars Azmun Inc; Tehran, Iran). Serum total cholesterol and HDL-cholesterol were measured using a cholesterol oxidase phenol aminoantipyrine and triglycerides using a glycerol-3 phosphate oxidase phenol aminoantipyrine enzymatic method. Serum LDL-cholesterol was calculated using the Friedwald formula; LDL-cholesterol was not calculated when triglycerides concentration was $>400 \mathrm{mg} / \mathrm{dl}$.

By the ADA criteria, an fasting plasma glucose of $126 \mathrm{mg} / \mathrm{dl}$ or greater or use of anti-diabetic measures was defined as diabetes [17].

The cut-points of serum total cholesterol (TC), HDL and LDL Cholesterol (LDL-C) and serum triglycerides (TG) distributions used to assign subjects at different 
levels of risk were those derived from the NCEP guidelines in the United States (Adult Treatment Panel III), September 2002 [18].

Measurement of CRP by a high-sensitivity CRP assay, CRP HS ELISA (DRG International, Inc. USA) was done. The minimum detectable concentration of the CRP HS ELISA was estimated to be $0.1 \mathrm{mg} / \mathrm{l}$. Additionally, the functional sensitivity was determined to be $0.1 \mathrm{mg} / \mathrm{l}$ (as determined with inter-assay $\%$ C.V. $<20 \%$ ). Elevated serum CRP was defined as more than $3.0 \mathrm{mg} / \mathrm{l}$.

\section{Statistical Methods}

The significance of the difference in the results of any two groups was determined by chi-square analysis using $2 \times 2$ contingency tables. A two-tailed t-test was used to compare the mean values across groups.

We found that log transformation of CRP gave a better fit to a Gaussian distribution. The geometric mean for CRP was defined as the arithmetic mean of the log-transformed data $+/-2 \mathrm{SD}$, raised to the power of 10. Multiple logistic regression analysis was used to ascertain the associations between diabetes and elevated CRP levels. Sex, age, smoking, LDL-cholesterol, HDL-cholesterol, hypertension, BMI, and elevated CRP ( $>3 \mathrm{mg} / \mathrm{l})$ were considered as covariates, and diabetes also as the dependent variable. $\mathrm{P}<0.05$ was considered statistically significant. Statistical analysis was performed with an IBM computer using the SPSS 9.05 statistical software package (SPSS Inc., Chicago, IL).

\section{Results}

A total of 1754 (49.2\% males, 50.8\% females) of the studied population were evaluated for associations of type 2 diabetes and serum levels of CRP.

An estimated $25.9 \%$ of the population was obese, $18.3 \%$ were smoker, $26.3 \%$ had hypertension, and $22.1 \%$ and $47.7 \%$ had high total cholesterol and low HDL-cholesterol levels, respectively. A total of $8.6 \%$ of the subjects $(8.0 \%$ of males $\& 9.1 \%$ of females; $\mathrm{p}>0.05$ ) had type 2 diabetes mellitus (ADA criteria).

Clinical characteristics, laboratory values and CRP levels in persons with and without diabetes were presented in Table 1. The geometric mean of CRP was $1.94 \mathrm{mg} / 1$ (3.80 SD) in the studied population. CRP levels were higher in women (geometric mean = $2.29 \mathrm{mg} / \mathrm{l})$ than men (geometric mean $=1.62 \mathrm{mg} / \mathrm{l})$, $(\mathrm{p}<0.0001)$. The subjects with diabetes had a higher geometric mean of CRP levels than the subjects without diabetes [3.67 (SD 3.71) versus 1.85 (3.83) respectively; $\mathrm{p}<0.0001)$ ] (Table 1). There was a significant correlation between elevated CRP and obesity [OR = 2.83, C.I (2.24-3.56); $\mathrm{p}<0.0001]$.

Table 2 shows age-adjusted odds ratios (95\% C.I)

Table 1. Clinical characteristics and laboratory values of a random population of the northern Persian Gulf with diabetes and normal fasting plasma glucose

\begin{tabular}{llcc}
\hline & Normal $(\mathrm{n}=1604)$ & Diabetes $(\mathrm{n}=150)$ & $P$ value \\
\hline Age, years & $40.02(11.42)$ & $49.06(10.63)$ & $<0.0001$ \\
Male, \% & 49.6 & 46.0 & N.S \\
Female, \% & 50.4 & 54.0 & N.S \\
BMI, kg/m2* & $27.14(5.2)$ & $28.2(6.3)$ & 0.03 \\
Systolic blood pressure, mmHg & $125.2(38.6)$ & $135.3(22.4)$ & 0.01 \\
Diastolic blood pressure, mmHg & $80.3(37.4)$ & $81.1(10.3)$ & 0.002 \\
Total Cholesterol, mg/dl & $203.3(46.2)$ & $236.6(53.4)$ & N.S \\
HDL-cholesterol, mg/dl & $44.9(39.5)$ & $43.2(10.2)$ & $<0.0001$ \\
LDL-cholesterol, mg/dl & $116.9(51.3)$ & $141.5(97.9)$ & N.S \\
Triglyceride, mg/dl & $166.6(100.7)$ & $215.3(111.8)$ & $<0.0001$ \\
Fasting plasma glucose, mg/dl & $82.6(13.0)$ & $194.5(76.2)$ & $<0.0001$ \\
C-reactive protein, mg/l ** & $1.8(3.8)$ & $3.6(3.7)$ & $<0.0001$ \\
Smoking, \% & 27.9 & 41.3 & 0.001 \\
\hline
\end{tabular}

Values are mean (SD), except for smoking, male and female

*BMI indicates body mass index

**Geometric mean (SD) 
Table 2. Multivariately odds ratios (OR) and 95\% CI relating type 2 diabetes as dependent variable, and elevated CRP levels $(>3.0 \mathrm{mg} / \mathrm{l})$ and associated risk factors as independent parameters in the Northern Persian Gulf adults.

\begin{tabular}{lccc}
\hline & \multicolumn{3}{c}{ Diabetes Mellitus } \\
\cline { 2 - 4 } & OR* & \multicolumn{1}{c}{$\mathrm{CI}^{*}$} & $P$ value \\
\hline Body Mass Index, kg/m² & 0.99 & $0.95-1.02$ & 0.65 \\
Systolic blood pressure, mmHg & 3.18 & $2.01-5.03$ & $<0.0001$ \\
Diastolic blood pressure, mmHg & 0.61 & $0.36-1.03$ & 0.06 \\
Triglyceride, mg/dl & 1.00 & $1.00-1.00$ & $<0.0001$ \\
HDL-cholesterol, mg/dl & 1.00 & $0.99-1.01$ & 0.17 \\
LDL-cholesterol, mg/dl & 1.01 & $1.00-1.01$ & $<0.0001$ \\
Smoking & 0.66 & $0.42-1.05$ & 0.08 \\
High CRP & 2.03 & $1.38-2.98$ & $<0.0001$ \\
\hline
\end{tabular}

*Adjusted for age and sex

between diabetes, cardiovascular risk factors, and elevated CRP levels (CRP $>=3 \mathrm{mg} / \mathrm{l})$.

In multiple logistic regression analysis, diabetes showed a significant association with elevated CRP levels $[\mathrm{OR}=2.76$, C.I (1.93 -3.94); $\mathrm{p}<0.0001]$ after adjusting for sex and age. The diabetes showed also a significant age-adjusted association with elevated CRP levels $[\mathrm{OR}=2.03$, C.I $(1.38-2.98) ; \mathrm{p}<0.0001]$ after adjusting for sex, LDL-cholesterol, HDL-cholesterol, blood pressure, smoking and BMI (Table 2).

\section{Discussion}

In the current study, we found that among the northern Persian Gulf adults, there was a highly significant association between type 2 diabetes and elevated CRP.

These data are compatible with the hypothesis that a subclinical inflammatory reaction may have a role in the pathogenesis of type 2 diabetes in Iranian adults in the northern Persian Gulf region.

CRP is produced by hepatocytes, and its gene expression is regulated by tumor necrosis factor- $\alpha$ and interleukin-6, which are secreted by adipocytes [19]. As a result, obese individuals who have more and larger adipocytes also have higher baseline serum CRP. Because diabetes is more common in obese individuals, an association is expected between serum CRP and diabetes. However, some studies found that obesity dose not explain the association of CRP with diabetes completely, suggesting an independent role for CRP in the development of diabetes [20-22]. The association of diabetes and elevated CRP remained in the study population after adjustment for obesity, blood pressure and cholesterol in a logistic regression model. We adjusted for the latter variables as surrogates of the metabolic syndrome, which could confound the association.

The CHS (Cardiovascular Heart Study), the Women's Health Study, the West of Scotland Coronary Prevention Study, the NHS (Nurses' Health Study) and the Rotterdam Study showed significant associations between CRP and incident diabetes, even after adjustment for obesity indices [7, 20, 21-23]. In contrast, the ARIC (Atherosclerosis Risk in Communities Study), the Monitoring of Trends and Determinants in Cardiovascular Diseases (MONICA)-Augsburg Cohort Study, and the IRAS (Insulin Resistance Atherosclerosis Study) showed no significant associations after adjustment for obesity indices [3, 22, 24]. There is a limited data about association of CRP and diabetes in Asian counties. In the general Japanese population, elevated CRP concentration was a significant predictor of diabetes, independent of obesity and insulin resistance [15]. In another study, CRP independently predicted the risk of remaining in impaired glucose tolerance (IGT) or progressing to diabetes in Chinese subjects with IGT [14].

Our finding adds to the growing body of evidence implicating low-grade inflammation as a potential dynamic in the pathogenesis of type 2 diabetes. Potential mechanisms for this relationship may be direct or indirect. For example, cytokines such as elevated levels of IL-6, which is known to be a main stimulator of the production of most acute-phase proteins, were shown to increase the risk of diabetes [23]. However, in addition to IL-6, other cytokines, such as interleukin (IL)$1 \beta$ of tumor necrosis factor- $\alpha$ (TNF- $\alpha$ ), are central mediators of inflammatory reactions. Tumor necrosis factor (TNF)- $\alpha$ may produce insulin resistance by influencing the function of the insulin receptor [25] or by stimulating adipocyte lipolysis [26,27]. It is well known that cytokines operate as a network in stimulating the production of acute-phase proteins. In particular, a combined elevation of IL- $1 \beta$ and IL- 6 , rather than the isolated elevation of IL- 6 alone, independently increases the risk of type 2 diabetes [28]. Alternatively, endothelial dysfunction may link inflammation to insulin resistance $[29,30]$. Some others explained the association through oxidative stress or innate immune system [23, 31]. However, further studies are necessary to find a reasonable mechanism. 
In addition, recent findings suggest that inflammation might not only play a possible role in diabetogenesis but also in hyperglycemia after diabetes has been established [32].Tan and et al. [14] have shown that in their cohort of IGT subjects, plasma CRP level was also a useful predictor. Those IGT subjects with plasma CRP levels in the top two quartiles had approximately three times the risk of either remaining in IGT or progressing to diabetes compared with those subjects with plasma CRP in the lowest quartile [14].

Strength of the present study is our general population sample, allowing generalization to the northern Persian Gulf population. However, several limitations of our study should be discussed. The primary limitation is that the participants were not uniformly screened for glucose intolerance; some cases of diabetes may have been undiagnosed. Therefore, we may not have fully captured the effects of inflammation in the postprandial period. If so, our findings may underestimate the strength of the true associations. A secondary limitation is that misclassification of exposure cannot be excluded since only one blood sample was taken for each participant for CRP testing. Even the baseline CRP value measured when the participant was free from acute infections might still not represent the usual CRP level during the long-term follow-up period due to within-person variability. This bias, referred to as regression dilution bias, could have also biased our findings.

In conclusion, we report a positive association between elevated CRP levels and diabetes which suggests a role for inflammation in the etiology of type 2 diabetes mellitus in the northern Persian Gulf population. The association was independent of established risk factors for diabetes. Further insight into the mechanisms involved in the etiology of diabetes and the specific effects of proinflammatory cytokines and acute-phase proteins will be essential for the development of new preventive strategies for diabetes mellitus.

\section{Acknowledgments}

This study was supported in part by a grant from Joint Ministry of Health and World Health Organization Regional Office (JPRM) fund (A/C: 02.01.01.01.ACS 2002-03), Bushehr Province Technology and Research Committee and Research Deputy of Bushehr University of Medical Science. We wish to thank Dr. Seyed Reza Imami and Dr. Abbass Nosrati for their kind assistance in field survey.

\section{References}

1. Pickup JC, Mattock MB, Chusney GD, Burt D (1997) NIDDM as a disease of the innate immune system: association of acute-phase reactants and interleukin-6 with metabolic syndrome X. Diabetologia 40: 12861292.

2. Pickup JC, Crook MA (1998) Is type II diabetes mellitus a disease of the innate immune system? Diabetologia 41: 1241-1248.

3. Festa A, D Agostino R Jr, Howard G, Mykkänen L, Tracy RP, Haffner SM ( 2000) Chronic subclinical inflammation as part of the insulin resistance syndrome: the Insulin Resistance Atherosclerosis Study (IRAS). Circulation 102: 42-47.

4. Yudkin JS, Stehouwer CD, Emeis JJ, Coppack SW (1999) C-reactive protein in healthy subjects: association with obesity, insulin resistance, and endothelial dysfunction: a potential role for cytokines originating from adipose tissue? Arterioscler Thromb Vasc Biol 19: 972-978.

5. Forouhi NG, Sattar N, McKeigue PM (2001) Relation of C-reative protein to body fat distribution and fea- tures of the metabolic syndrome in Europeans and South Asians. Int J Obes 25: 1324-1328.

6. Komatsu M, Ohfusa H, Aizawa T, Hashizume K (2007) Adiponectin inversely correlates with high sensitive C-reactive protein and triglycerides, but not with insulin sensitivity, in apparently healthy Japanese men. Endocr J 54: 553-558.

7. Dehghan A, Kardys I, de Maat MPM, Uitterlinden AG, Sijbrands EJG, Bootsma AH, Stijnen T, Hofman A, Schram MT, Witteman JCM (2007) Genetic variation, C-reactive protein levels, and incidence of diabetes. Diabetes 56: 872-878.

8. Jialal I, Devaraj S, Venugopal SK (2004) C-reactive protein: risk marker or mediator in atherothrombosis? Hypertension 44: 6-11.

9. Ridker PM (2003) Clinical application of C-reactive protein for cardiovascular disease detection and prevention. Circulation 107: 363-369.

10. Pearson TA, Mensah GA, Alexander RW, Anderson JL, Cannon RO III, Criqui M, Fadl YY, Fortmann SP, Hong Y, Myers GL, Rifai N, Smith SC Jr, Taubert K, 
Tracy RP, Vinicor F; Centers for Disease Control and Prevention; American Heart Association (2003) Markers of inflammation and cardiovascular disease: application to clinical and public health practice/A Statement for Healthcare Professionals. Circulation 107: 499-511.

11. Dondona P, Aljada A, Chaudhuri A, Bandyopadhyay A (2003) The potential influence of inflammation and insulin resistance on the pathogenesis and treatment of atherosclerosis-related complications in type 2 diabetes. J Clin Endocrinol Metab 88: 2422-2429.

12. Schulze MB, Rimm EB, Li T, Rifai N, Stampfer MJ, $\mathrm{Hu}$ FB (2004) C-reactive protein and incident cardiovascular events among men with diabetes. Diabetes Care 27: 889-894.

13. Vahdat K, Jafari SM, Pazoki R, Nabipour I (2007) Concurrent increased high sensitivity $\mathrm{C}$-reactive protein and chronic infections are associated with coronary artery disease: a population-based study. Indian J Med Sci 61: 135-143.

14. Tan KCB, Wat NMS, Tam SCF, Janus ED, Lam TH, Lam KSL (2003) C-reactive protein predicts the deterioration of glycemia in Chinese subjects with impaired glucose tolerance. Diabetes Care 26: 2323-2328.

15. Doi Y, Kiyohara Y, Kubo M, Ninomiya T, Wakugawa Y, Yonemoto K, Iwase M, Iida M (2005) Elevated $\mathrm{C}$-reactive protein is a predictor of the development of diabetes in a general Japanese population. Diabetes Care 28: 2497-2500.

16. World Health Organisation (2000) Obesity: preventing and managing the global epidemic: report of a WHO consultation, Geneva. WHO Technical Report Series 894.

17. Report of the Expert Committee on the Diagnosis and Classification of Diabetes Mellitus. Diabetes Care (1997) 20: 1183-1197.

18. Third Report of the Expert Panel on Detection, Evalution, and Treatment of high blood cholesterol in Adults (2004) Adult treatment Panel III. http://www.nhlbi. nih.gov/guidelines/cholesterol.

19. Trayhurn P, Beattie JH (2001) Physiological role of adipose tissue: white adipose tissue as an endocrine and secretory organ. Proc Nutr Soc 60: 329-339.

20. Barzilay JI, Abraham L, Heckbert SR, Cushman M, Kuller LH, Resnick HE, Tracy RP(2001) The relation of markers of inflammation to the development of glucose disorders in the elderly: the Cardiovascular Health study. Diabetes 50: 2384-2389.

21. Hu FB, Meigs JB, Li TY, Rifai N, Manson JE (2004) Inflammatory markers and risk of developing type 2 diabetes in women. Diabetes 53: 693-700.

22. Freeman DJ, Norrie J, Caslake MJ, Gaw A, Ford I, Lowe GD, O'Reilly DS, Packard CJ, Sattar N (2002) West of Scotland Coronary Prevention Study: C-reactive protein is an independent predictor of risk for the development of diabetes in the West of Scotland Coronary Prevention Study. Diabetes 51: 1596-1600.

23. Pradhan AD, Manson JE, Rifai N, Buring JE, Ridker PM (2001) C-reactive protein, interleukin 6, and risk of developing type 2 diabetes mellitus. JAMA 286: $327-$ 334.

24. Thorand B, Lowel H, Schneider A, Kolb H, Meisinger C, Frohlich M, Koenig W (2003) C-reactive protein as a predictor for incident diabetes mellitus among middle-aged men: results from the MONICA Augsburg Cohort study, 1984-1998. Arch Intern Med 163: 9399.

25. Hotamisligil GS, Peraldi P, Budavari A, Ellis R, White MF, Spiegelman BM (1996) IRS-1 mediated inhibition of the insulin receptor tyrosine kinase activity in TNFalpha- and obesity-induced insulin resistance. Science 271: 665-668.

26. Chajek-Shaul T, Friedman G, Stein O, Shiloni E, Etienne J, Stein Y (1989) Mechanism of hypertriglyceridaemia induced by tumour necrosis factor administration to rats. Biochim Biophys Acta 1001: 316-324.

27. Bjorntorp P (1994) Fatty acids, hyperinsulinaemia, and insulin resistance: which comes first? Curr Opin Lipidol 5: 166-174.

28. Spranger J, Kroke A, Mohlig M, Hoffmann K, Bergmann MM, Ristow M, Boeing H, Pfeiffer AF (2003) Inflammatory cytokines and the risk to develop type 2 diabetes: results of the prospective populationbased European Prospective Investigation into Cancer and Nutrition (EPIC)-Potsdam Study. Diabetes 52: 812-817.

29. Cleland SJ, Sattar N, Petrie JR, Forouhi NG, Elliott HL, Connell JM (2000) Endothelial dysfunction as a possible link between C-reactive protein levels and cardiovascular disease. Clin Science 98: 531-535.

30. Tooke J (1999) The association between insulin resistance and endotheliopathy. Diabetes Obes Metab 1(Suppl. 1): S17-S22.

31. Nakanishi S, Yamane K, Kamei N, Okubo M, Kohno $\mathrm{N}$ (2003) Elevated C-reactive protein is a risk factor for the development of type 2 diabetes in Japanese Americans. Diabetes Care 26: 2754-2757.

32. King DE, Mainous AG 3rd, Buchanan TA, Pearson WS (2003) C-reactive protein and glycemic control in adults with diabetes. Diabetes Care 26: 1535-1539. 